
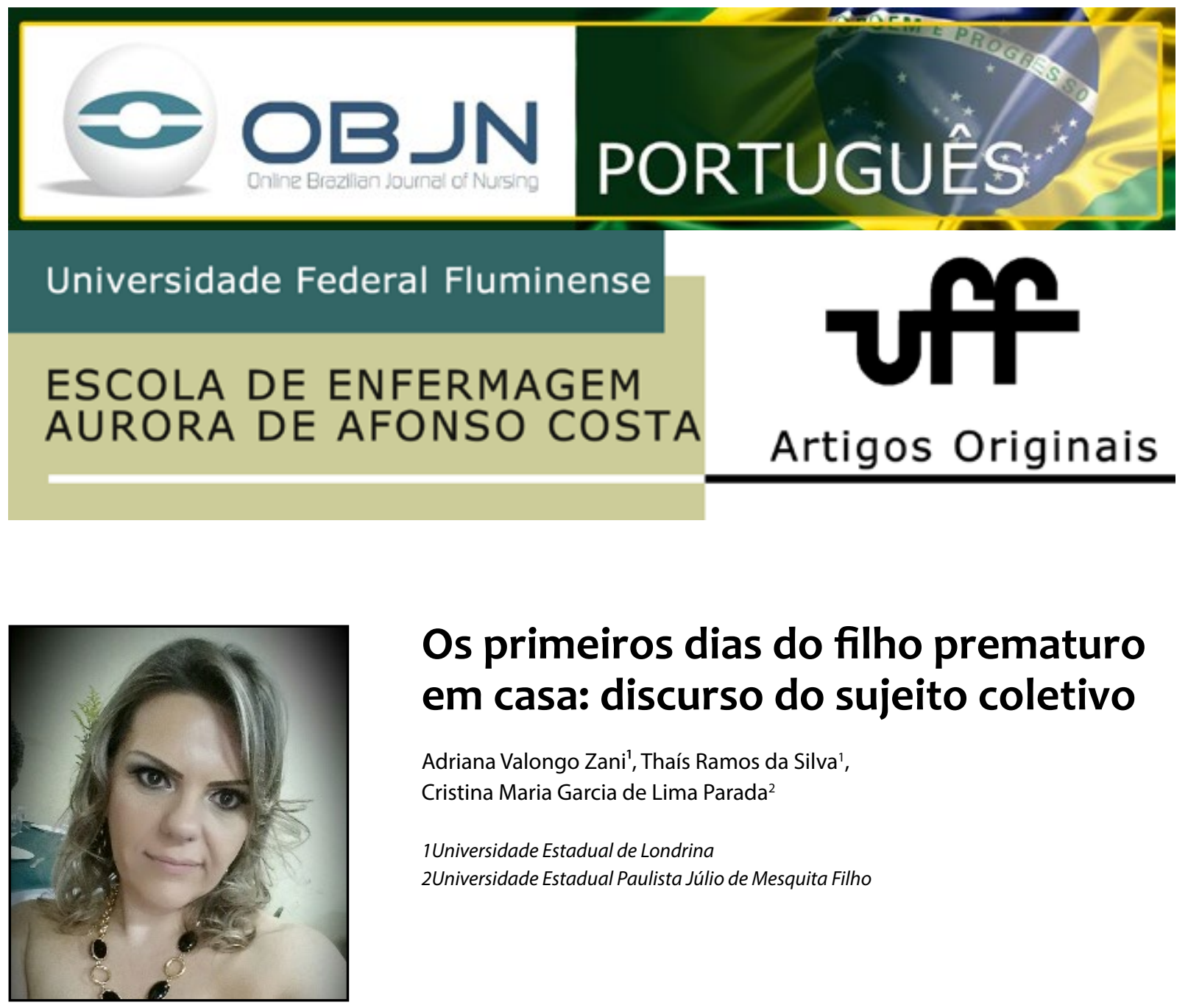

\title{
Os primeiros dias do filho prematuro em casa: discurso do sujeito coletivo
}

\author{
Adriana Valongo Zani ${ }^{1}$, Thaís Ramos da Silva', \\ Cristina Maria Garcia de Lima Parada² \\ 1Universidade Estadual de Londrina \\ ZUniversidade Estadual Paulista Júlio de Mesquita Filho
}

\section{RESUMO}

Objetivo: apreender as representações do pai frente ao cuidado do filho prematuro nos primeiros dias após a alta hospitalar. Método: estudo de abordagem qualitativa. Participaram sete pais que possuíam filhos prematuros hospitalizados em uma unidade de terapia intensiva neonatal. A coleta de dados ocorreu no período de março a junho de 2015. Para análise dos dados, utilizou-se o referencial metodológico do discurso do sujeito coletivo. Resultados: os discursos foram agrupados em três temas: 1) Vivendo as emoções da primeira noite com o filho em casa; 2) Responsabilizando-se pelo cuidado do filho prematuro em casa;

3) Colocando em prática os cuidados aprendidos com a equipe de enfermagem durante a hospitalização. Conclusão: o pai tem participado do cuidado do filh . A equipe de enfermagem deve estar preparada para incentivar a presença do pai no ambiente hospitalar, envolvendo-o nos cuidados precocemente, para que possa sentir-se mais seguro no momento em que estiver com o filho no domicíli .

Descritores: Paternidade; Alta do Paciente; Recém-Nascido; Prematuro. 


\section{INTRODUÇÃO}

Recém-nascidos com idade gestacional abaixo de 37 semanas são classificados como prematuros, sendo esta situação considerada a principal causa de mortalidade neonatal na atualidade(1).

Em decorrência dos riscos à vida que a prematuridade pode acarretar, estes bebês podem ser separados de seus pais logo após o parto, sendo encaminhados à Unidade de Terapia Intensiva Neonatal (UTIN) para que possam receber cuidados específi os, o que dificulta a formação de vínculo entre o bebê e os pais ${ }^{(2)}$. Como consequência deste fato, surgem na família, principalmente nos pais, sentimentos negativos como angústia, tristeza, incerteza e medo da morte ${ }^{(3)}$.

Neste contexto, os profissionais de saúde atuantes nas UTIN desempenham papel fundamental, promovendo a formação desse vínculo e auxiliando na superação desta fase difícil e delicada para os pais e recém-nascidos. Assim, a equipe deve estar sensibilizada e capacitada para cuidar da família e sugerir ações que reduzam seu sofrimento e promovam empoderamento, compartilhando informações e incentivando a participação dos pais no cuidado, respeitando seu tempo e limites ${ }^{(4)}$.

Os cuidados promovidos na UTIN pelos pais podem amenizar o sofrimento pelo nascimento prematuro do filh , proporcionando o fortalecimento do vínculo pais-bebê, bem como contribuir para que adquiram segurança na execução dos cuidados, garantindo o cuidado futuro, após a alta hospitalar ${ }^{(5)}$.

De modo geral, a figu a materna se mostra mais presente no cuidado, pois, historicamente, no âmbito familiar e cultural, a mulher tem desempenhado papel de cuidadora do lar e dos filho , cabendo ao homem papel de provedor do sustento da família. Porém, nos dias atuais, com as intensas mudanças sociais ocorridas, a mulher tem enfrentado o mercado de trabalho em busca de novas possibilidades, novas conquistas e novos modelos de vida(6), resultando em mudanças profundas nas famílias, inclusive na figura do pai, que passa a ter uma participação igualitária e ativa na criação dos filho , contribuindo com o cuidado e partilhando responsabilidades e decisões sobre o filh ${ }^{(7)}$.

Em geral, durante a internação em UTIN, o pai é o primeiro a visitar o filho e a receber informações dos profissionais de saúde. Enfrentando a hospitalização, muitas vezes é o responsável por dar à mãe informações sobre a situação, visto que esta também pode estar necessitando de cuidados e, assim, impossibilitada de ver o filho após o nascimento ${ }^{(8)}$.

O pai vem assumindo dia-a-dia novos papéis na família, dividindo com a companheira, muitas vezes fragilizada, as atividades domésticas, estimulando e apoiando o aleitamento materno, contribuindo para o sucesso do mesmo(9). Para além do período de hospitalização, seu papel se amplia no domicílio. Como cuidador, interage de modo diferente com o filh, introduzindo novidades e desafio, contribuindo com o desenvolvimento cognitivo e empático da criança com os pais ${ }^{(10)}$. Pode estar envolvido de muitas formas com o bebê: brincando, cuidando, ensinando, provendo suporte financeiro, demonstrando afeto, compartilhando com a mãe atividades, responsabilidades e preocupações a respeito da criança ${ }^{(7)}$. Partindo desses pressupostos, o objetivo deste estudo foi apreender as representações do pai frente ao cuidado do filho prematuro nos primeiros dias após a alta hospitalar.

\section{MÉTODO}

De abordagem qualitativa, este estudo integra um amplo projeto de pesquisa intitulado: 
"A figu a paterna no cuidado ao recém-nascido prematuro e de baixo peso hospitalizado em Unidade de Terapia Intensiva Neonatal".

O cenário do estudo foi a UTIN de um hospital escola localizado na região norte do Paraná. Credenciado pelo Sistema Único de Saúde (SUS), este hospital atua na prestação de assistência à saúde em praticamente todas as especialidades médicas, formação de recursos humanos, educação continuada, pesquisa e desenvolvimento tecnológico e realiza cooperação técnica e científica com a rede de serviços de saúde de Londrina. A estrutura é constituída de unidades de internação médico-cirúrgicas e pediátrica, além de maternidade, centro-cirúrgico, pronto-socorro e UTI adulto, pediátrica e neonatal. $\mathrm{Na}$ área neonatal, a UTI possui sete leitos e a Unidade de Cuidados Intermediários (UCI), oito leitos.

Participaram deste estudo sete pais que possuíam filhos prematuros hospitalizados na UTIN. Estes foram convidados a participar do estudo pelas pesquisadoras, sendo informados sobre os objetivos da pesquisa, procedimentos de coleta de dados, sigilo no tratamento das informações, possíveis riscos e possibilidade de interromper a participação a qualquer momento, sem prejuízo ao cuidado do filh . Com sua concordância, solicitava-se assinatura do termo de consentimento livre e esclarecido.

Foram critérios de inclusão: ser pai de bebê nascido com idade gestacional menor que 34 semanas, com peso igual ou inferior a $1500 \mathrm{~g}$ e ter recebido alta hospitalar no período de março a junho de 2015. Os critérios de exclusão adotados foram: ser pai de criança portadora de malformações congênitas (um caso) ou que tenha evoluído para óbito no período do seguimento (quatro casos).

A duração média do encontro das pesquisadoras com os participantes foi de 30 minutos, considerando a interação inicial e a entrevista propriamente dita.
As entrevistas foram gravadas utilizando-se gravador digital e foi utilizado um caderno de campo para síntese do pesquisador. Ao término da entrevista solicitava-se ao pai que ouvisse a gravação da entrevista e a leitura da síntese realizada, garantindo a ele o direito de alterar as informações, caso julgasse necessário. As entrevistas foram realizadas no domicilio das famílias sete dias após a alta dos filho .

A coleta de dados foi realizada no período de março a junho de 2015, por meio de entrevista semiestruturada. As questões norteadoras utilizadas na entrevista, para motivar a fala dos pais, foram: Conte-me, como foi o primeiro dia que você passou com seu filho em casa? Como tem sido distribuído o cuidado do seu filho Em relação às orientações que você recebeu no hospital, sobre os cuidados com seu filh , elas tiveram alguma influência para você aqui no domicilio?

Os dados foram trabalhados de acordo com o referencial teórico das Representações Sociais, que constituem uma série de opiniões, explicações e afi mações produzidas a partir do cotidiano dos grupos, sendo a comunicação elemento primordial neste processo. Considerada teoria do senso comum, por serem criadas pelos grupos como forma de explicação da realidade, a representação social formaliza uma modalidade de conhecimento particular que tem por função a elaboração de comportamentos e a comunicação entre indivíduos ${ }^{(11)}$. O referencial metodológico adotado foi o Discurso do Sujeito Coletivo (DSC) que propõe a organização e tabulação de dados de natureza qualitativa de forma discursiva, procurando tornar claro o que pensa ou a vivência de determinada população sobre certo tema.

A proposta do DSC consiste em analisar o material verbal coletado, extraindo-se dos discursos algumas figu as metodológicas para organizar, apresentar e analisar os dados obtidos 
a partir dos depoimentos. As figu as metodológicas que auxiliam na análise dos dados são: as expressões-chave, as idéias centrais, o discurso do sujeito coletivo e a ancoragem ${ }^{(12)}$.

O Discurso do Sujeito Coletivo é construído na primeira pessoa do singular, buscando reconstruir com pedaços de discursos individuais, como quebra-cabeça, tantos discursos-síntese quantos se julguem necessários para expressar o pensamento ou representação social de um grupo de pessoas sobre determinado tema ${ }^{(12)}$. A representatividade do grupo na fala do indivíduo ocorre porque tanto o comportamento social quanto o individual obedecem a modelos culturais interiorizados, ainda que as expressões pessoais apresentem sempre variações em confli o com as tradições. A questão da representatividade qualitativa refle e o caráter histórico mais geral e específi o de um grupo ${ }^{(13)}$.

O estudo foi aprovado pelo Comitê de Ética em Pesquisa da Universidade Estadual de Londrina - UEL, mediante CAAE $n$. 30709814.0.0000.5231, conforme parecer $n^{\circ}$ 694.303.

\section{RESULTADOS}

Breve caracterização dos pais indica idade entre 20 e 44 anos; três possuíam ensino fundamental incompleto, três ensino médio completo e um ensino fundamental completo; sobre o estado civil, quatro se declararam casados, dois em união consensual (com tempo de união variando de oito meses a sete anos) e um divorciado; quatro estavam vivenciando pela primeira vez a paternidade e três já possuíam outros filho . Sobre a renda familiar, três referiram ser em torno de dois salários mínimos, dois citaram três salários mínimos e dois pais, mais que três salários mínimos.
Do material empírico analisado, emergiram seis ideias centrais (IC), as quais foram agrupadas em três temas: 1) Vivendo as emoções da primeira noite com o filho em casa (IC1- A primeira noite foi tranquila; IC2- Na primeira noite ninguém dormiu); 2) Responsabilizando-se pelo cuidado do filho prematuro em casa (IC3- Participação efetiva do pai nos cuidados do filho; IC4- Auxiliando nos afazeres domésticos) e 3) Colocando em prática os cuidados aprendidos com a equipe de enfermagem durante a hospitalização (IC5- Orientações das enfermeiras sobre os cuidados básicos com o filho foram importantes; IC6 - Os ensinamentos das enfermeiras sobre os principais sinais de perigo com o prematuro proporcionaram tranquilidade).

Para melhor compreensão da análise realizada e preservação do anonimato dos participantes, o nome dos pais foi substituído pela letra $P$, seguida de sequência numérica, a partir da ordem de realização das entrevistas.

Tema 1: Vivendo as emoções da primeira noite com o filho em casa

IC1- A primeira noite foi tranquila

DSC1- A primeira noite foi sossegada, tranquila, foi muito bom, estávamos na expectativa da alta da internação. A gente fica preocupado com o risco do hospital, pelo risco de contaminação. Eles são frágeis, têm a imunidade baixa. Assim, ficamos muito felizes de ter nosso filho em casa. Foi bacana, o nosso sonho era de ter ele aqui. Não tem como descrever a alegria! (P1, P4-P7)

Como observado no DSC1, os pais representaram os filhos como frágeis e a impropriedade do ambiente hospitalar. Mostraram-se preocupados, ancorados no risco de contaminação hospitalar, razão pela qual se sentiram felizes com a alta e chegada em casa. Por outro lado, 
dificuldades na chegada em casa também foram relatadas, como consta do DSC2.

IC2- Na primeira noite ninguém dormiu

DSC2- O primeiro dia foi diferente, foi bem trabalhoso, ele chorou bastante à noite, não deixou ninguém dormir, porque teve que se adaptar, no hospital era diferente, outro ambiente. Tinha movimento à noite, então em casa todos acordavam também. Foi diferente, uma experiência diferente do normal. (P1-P4)

O primeiro dia em casa com o filho apesar de ser um momento de felicidade também é tomado por sentimentos de insegurança, pois tanto os pais como o filho precisam se adaptar ao novo ambiente domiciliar e rotinas antes desconhecidas.

Tema 2-Responsabilizando-se pelo cuidado do filho prematuro em casa

IC3- Participação efetiva do pai nos cuidados do filh

DSC3- Quando eu posso, eu ajudo. Procuro ficar durante a noite com nosso filh, quando chego do trabalho: troco fraldas, dou remédio, ajudo no banho e acordo minha esposa quando o bebê quer mamar, depois pego o bebê de novo para dormir. (P1-P7)

Os pais representaram o cuidado a partir de tarefas cotidianas desenvolvidas com o filh , assumidas ao chegar do trabalho (DSC3), bem como apontaram a realização de tarefas domésticas, como forma de deixar a esposa mais livre para o cuidado do filh, como relatado no DSC4.

IC4- Auxiliando nos afazeres domésticos

DSC4- Eu também ajudo a cuidar da casa para que minha esposa tenha mais tempo para cuidar do nosso bebê: lavo roupa, lavo louça, faço janta e limpo a casa... e quando minha esposa vai cuidar da casa eu fi o brincando com nosso filh , ou pego ele no colo para ajudá-la.

\section{(P2-P5, P7)}

O auxílio do pai nas tarefas domésticas propicia que a mãe possa fortalecer o vínculo com seu filho recém-chegado e, consequentemente, os laços matrimoniais são fortalecidos.

Tema 3- Colocando em prática os cuidados aprendidos com a equipe de enfermagem durante a hospitalização

Os pais representaram o cuidado aprendido com apoio da equipe de enfermagem a partir do aconchego e conforto, mas também de ações práticas, como banho e troca de fraldas. Ancoraram suas necessidades não apenas no fato de serem inexperientes, mas também nas maiores demandas de bebês prematuros, aspectos que emergiram do DSC5:

IC5- Orientações das enfermeiras sobre os cuidados básicos com o filho foram importantes

DSC5: As enfermeiras no hospital nos ensinaram muito sobre como cuidar do nosso bebê: elas ensinaram a fazer o ninho para dormir e sentir como se ainda estivesse dentro da barriga da minha esposa, como agasalhar, usar a fraldinha embaixo do ombro, porque a cabeça é mais alta que o corpo... aprendi como trocar fraldas, dar o banho com o nenê enrolado na fralda, pois se fi er sem fralda ele fica perdido, tampar o ouvidinho para não entrar água. Aprendi muito, principalmente por ser pai de primeira viagem, de bebê prematuro e ao acompanhar a internação aprendi que o bebê só chora por quatro coisas: fome, fralda suja de xixi ou de cocô ou porque está com dor. Se ele está alimentado, limpinho, e chora, pode ter outra coisa. No começo eu e 
minha esposa sofremos muito pelas cólicas, dava muita cólica, mas começávamos a estimular com exercício no abdome e nos pezinhos, aí ele fazia cocô e melhorava. Após isso ele dormia bem.

\section{(P2-P7)}

Após vivenciar a internação hospitalar de filhos prematuros, termos médicos técnicos passam a compor os discursos dos pais, como consta do DSC6. Compreender o significado destes e formas de atender eventuais demandas é importante para eles e os tranquiliza.

IC6 - Os ensinamentos das enfermeiras sobre os principais sinais de perigo com o prematuro proporcionaram tranquilidade

DSC 6: Se todos os pais tivessem a oportunidade que tive, de saber o que é apneia, engasgo... com certeza eles também fica iam mais tranquilos, como eu. Hoje eu consigo trabalhar com tranquilidade. As enfermeiras nos ensinaram muito, todo o aprendizado foi muito válido, pois tudo que aprendi com elas utilizo aqui em casa e sempre dá certo. (P4-P7)

\section{DISCUSSÃO}

Com a inserção da mulher no mercado de trabalho e sua participação efetiva no sustento da casa, os homens estão cada vez mais próximos dos cuidados domésticos e dos filho . O nascimento de um filho pré-termo pode implicar ainda mais nessa participação, uma vez que, com a hospitalização do filh , a esposa passa a desempenhar exclusivamente o papel de mãe, ausentando-se de casa para permanecer com o filho hospitalizado, necessitando de maior apoio e auxílio do companheiro nos afazeres domésticos e, por vezes, no cuidado com outros filho ${ }^{(14)}$.

Após a alta, mesmo com as orientações recebidas, podem surgir sentimentos de inse- gurança, medo e ansiedade no âmbito familiar, uma vez que o filho que permaneceu grande parte do tempo sob o cuidado dos profissionais de saúde, agora deverá ser cuidado exclusivamente por sua família, sem o auxílio dos profi sionais e fora do ambiente hospitalar.

Durante a primeira noite em casa, surgiram sentimentos diversos entre os pais, entre eles alguns negativos, como o cansaço, decorrente de uma noite mal dormida, pela necessidade de adaptação do recém-nascido, adaptação esta que repercute diretamente na vida familiar, onde os pais, principais cuidadores, precisam modificar hábitos, passando a considerar aqueles já adquiridos pelo bebê hospitalizado. Após a chegada desse filho em casa ocorrem várias mudanças, como: necessidade de priorizá-lo, adaptação ao seu ritmo e dedicação a ele, já que o filho é totalmente dependente dos pais ${ }^{(7)}$.

Muitas vezes, o nascimento de um filh também promove algumas mudanças negativas na qualidade conjugal, especialmente em situações que demandam mais cuidados, como no caso do nascimento prematuro. Os cuidados ao bebê são bem diferentes dos esperados antes do nascimento, ainda mais quando as expectativas são violadas. Além disso, a adaptação à paternidade implica muitas vezes em maior compromisso com o relacionamento como pais e menor como cônjuges ${ }^{(15)}$.

Em contraponto a esses sentimentos negativos, alguns pais referiram a primeira noite como tranquila e até mesmo como esperada, já que o sentimento maior era de ter o filh em casa. A própria internação muitas vezes prolongada, gera nesses pais ansiedade para a alta hospitalar e chegada do filho no domicílio, e quando isso ocorre surgem sentimentos de alegria e satisfação(16). Os pais com expectativas boas antes do nascimento em relação ao filh , após o nascimento participam de forma mais 
efetiva, com satisfação conjugal e menor desgaste nessa fase de transição(15).

As contrastantes experiências positivas e negativas podem estar relacionadas com as fases do novo papel parental, sendo a maioria das respostas emocionais durante a gravideze até dois anos após o nascimento mais negativas do que positivas. As emoções negativas como surpresa, e confusão, observadas em alguns discursos, estão associadas com a transição para a paternidade, assim como emoções positivas que variam de alegria, ansiedade e tristeza geram flutuação de sentimentos característicos do processo de parentalidade ${ }^{(17)}$. Os discursos dos pais revelam participação cada vez mais ativa e frequente dos mesmos nos cuidados diretos aos filho, corroborando com achados de outro estudo semelhante, que encontrou como principais atividades de cuidado do bebê realizado pelos pais: trocar fraldas, realização do banho, oferecer colo, alimentar, preparo e oferta de mamadeira ou alimentos pastosos, atenção durante a noite e cuidado em saúde, levando ao médico, dando-lhe remédio ou observando hábitos de higiene e prevenção de doença ${ }^{(7)}$.

O estudo revelou que os pais não apenas estão realizando cuidados diretos ao filh , mas auxiliando suas companheiras nos afazeres domésticos e, assim, propiciando que as mesmas tenham mais tempo para dedicar-se aos cuidados do filh ${ }^{(15)}$.

O pai deseja passar mais tempo com seu filh , sendo este tempo considerado como experiência positiva ${ }^{(17)}$. Atividades como brincar, pegar no colo, entre outras, são consideradas prazerosas e satisfatórias para os pais ${ }^{(7)}$.

É importante enfatizar que a comunicação da equipe de enfermagem com a família favorece o surgimento de vínculo de confiança e respeito, contribuindo com a qualidade do cuidado prestado ao recém-nascido(18).

A equipe de enfermagem exerce papel fundamental na educação em saúde, capacitando mães e pais na realização de cuidados aos filho . Muitas vezes pela prematuridade e/ou risco do filh , os pais sentem receio e medo de assumir esse cuidado, necessitando de apoio e orientação da equipe de enfermagem para realizá-los. No presente estudo, esse apoio foi reconhecido pelos pais como essencial.

O enfermeiro atua na avaliação e cuidados diretos ao recém-nascido hospitalizado, bem como a sua família, oferecendo apoio e escuta, orientando e informando-os sobre a prematuridade e preparando-os para o processo de alta e cuidados no domicilio ${ }^{(16,19)}$.

Os cuidados e orientações realizadas pela equipe de enfermagem à família durante a hospitalização dos filhos foram importantes para a redução dos medos e dúvidas dos pais a respeito do cuidado com seus filho, permitindo que os mesmos fi essem parte dos cuidados. Isso é possível porque a equipe de enfermagem pode delegar aos pais os cuidados mais simples, realizando os procedimentos técnicos, mais complexos. A equipe deve encorajar a família na assistência ao bebê, assegurando, assim, cuidado de qualidade no futuro, inclusive após a alta hospitalar ${ }^{(5,20)}$.

\section{CONCLUSÃO}

Considera-se que o objetivo do estudo foi atingido, visto que foi possível apreender as representações do pai frente ao cuidado do filho prematuro nos primeiros dias após a alta hospitalar. Dentre as emoções frente a primeira noite do filho em casa, emergiram sentimentos de felicidade e tranquilidade, mas também de estresse e dificuldades em compreender o que o filho desej va e porque chorava.

Também emergiram dos discursos dos pais maior envolvimento nos cuidados diretos ao filh , se responsabilizando pelos cuidados, bem 
como auxiliando sua companheira nos afazeres domésticos para que ela pudesse ter mais tempo para o cuidado do filh .

Evidenciou-se no presente estudo a valorização atribuída pelo pai às orientações e cuidados ensinados pela equipe de enfermagem no ambiente hospitalar, que vieram a contribuir na redução dos medos e ansiedade quando do cuidado no domicilio.

Assim, cabe salientar que o pai deseja e tem participado efetivamente do cuidado do filh .Cabe à equipe de enfermagem, bem como aos demais profissionais atuantes nas unidades neonatais, estarem preparados para incentivar a presença do pai no ambiente hospitalar, envolvendo-os o mais precocemente possível nos cuidados ao filho, mesmo que com cuidados simples, de forma que ele possa se familiarizar com o novo membro da família e deste modo fortalecer o vínculo familiar.

\section{REFERÊNCIAS}

1. Organização Mundial da Saúde. Nascimentos prematuros. Nota descritiva $\mathrm{N}^{\circ} 363$. [Cited 2015 August 31] 2013. Available from: http://www. who.int/mediacentre/factsheets/fs363/es/.

2. Ministério da Saúde (BR). Secretaria de Atenção à Saúde. Departamento de Ações Programáticas Estratégicas. Atenção humanizada ao recém-nascido de baixo peso: Método Canguru/ Ministério da Saúde, Secretaria de Atenção à Saúde, Departamento de Ações Programáticas Estratégicas. - 2. ed. - Brasília: Editora do Ministério da Saúde, 2011.

3. Zani A, Golias A, Martins S, Parada C, Marcon S, Tonete VL, Parada CMG. Feelings experienced by the family of na at-risk newborn infant: integrative literature review. Journal of Nursing UFPE. 2013 November [Cited 2015 Agust 10]. 7(1). Available from: http://www.revista.ufpe.br/ revistaenfermagem/index.php/revista/article/ viewArticle/2610.
4. Amador DD, Marques FRB, Duarte AM, Balbino FS, Balieiro MMFG, Mandetta MA. Use of narrative as an awareness strategy for a Family-Centered Care model. Rev Gaúcha Enferm. 2015 March; 36(1):98-103.

5. Pacheco STA, Rodrigues BMRD, Dionísio MCR, Machado ACC, Coutinho KAA, Gomes APR. Family-centered care: nursing application in the context of the hospitalized child. Rev. Enferm. UERJ. 2013; 21(1):106-12.

6. Lopes MN, Zanon LLD, Boeckel MG. A Multiplicidade de Papéis da Mulher Contemporânea e a Maternidade Tardia. Trends in Psychology / Temas em Psicologia. 2014; 22(4): 917-928.

7. Piccinini CA, Silva MR, Gonçalves TR, Lopes, RCS. Fathers'Involvement During the Baby's Third Month. Psicologia:Teoria e Pesquisa. 2012; 28 (3):303-314.

8. Cañas-Lopera EM, Rodríguez-Holguín YA. La experiencia del padre durante la hospitalización de su hijo recién nacido pretérmino extremo. Aquichan. 2014; 14 (3): 336-350.

9. Paula AO, Sartori AL, Martins CA. Aleitamento materno: orientações, conhecimento e participação do pai nesse processo. Rev. Eletr. Enf. [Internet]. 2010 [Cited 2015 August 10] 12(3). Available from: http://dx.doi.org/10.5216/ree.v12i3.6929

10. Landesem IP, Handegard BH, Ulvund JTSE, Ronning JÁ. Early intervention program reduces stress in parents of preterms during childhood, a randomized controlled trial. Trials 2014 [Cited 2016 Januario 20] 15(387). Available from: http:// www.trialsjournal.com/content/15/1/387.

11. Jodelet $D$. Loucuras e representação social. Petrópolis: Vozes; 2005.

12. Lefevre F.; Lefevre AMC. Pesquisa de Representação Social. Um enfoque qualiquantitativo. São Paulo: Liberlivro, 2011.

13. Minayo M.C.S. O desafio do conhecimento.

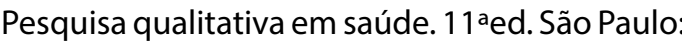
HUCITEC/ABRASCO, 2014.

14. Ghosh JK, Wilhelm MH, Dunkel-Schetter C, Lombardi CA, Ritz BR. Paternal support and preterm birth, and the moderation of effects of chronic stress: a study in Los Angeles county mothers. Arch Womens Ment Health. August 2010 [Cited 2016 Januario 10] 13(4). Available from: http://www.ncbi.nlm.nih.gov/pmc/articles/ PMC2896639/?tool=pubmed. 
15. Menéndez $S$, Hidalgo MA, Jiménez $L$, Moreno MC. Father Involvement and Marital Relationship during Transition to Parenthood: Differences between Dual and Single-Earner Families. The Spanish Journal of Psychology .2011; 14 (2):639-647.

16. Lopez GL, Anderson KH, Feutchinger J.Transition of Premature Infants From Hospital to Home Life. Neonatal Netw. 2012; 31(4): 207-214.

17. Benzies KM, Magill - Evans J. Through the eyes of a new dad: experiences of firs -time fathers of late-preterm infants. Infant Mental Health Journal. 2015; 36(1): 78-87.

18. Zani AV, Tonete VLP, Lima CMGP. Maternal representations about the provision of care to newborns at risk: a collective discourse. Online Braz J Nurs [internet] 2014 September [Cited 2015 August 10]; 13 (3). Available from: http://www. objnursing.uff.br/index.php/nursing/article/ view/4328/html_171.

19. Souza NL, Fernandes ACP, Clara-Costa IC, Cruz-Enders B, Carvalho JBL, Silva MLC. Domestic maternal experience with preterm newborn children. Rev. Salud Pública. 2010; 12 (3): 356-367.

20. Stevens EE, Gazza E, Pickler R. Parental experience learning to feed their preterm infants. Adv Neonatal Care. 2014 Ocober. [Cited August 10] 14(5). Available from: http://www.ncbi.nlm.nih. gov/pmc/articles/PMC4139421/?tool=pubmed.
Todos os autores participaram das fases dessa publicação em uma ou mais etapas a seguir, de acordo com as recomendações do International Committe of Medical Journal Editors (ICMJE, 2013): (a) participação substancial na concepção ou confecção do manuscrito ou da coleta, análise ou interpretação dos dados; (b) elaboração do trabalho ou realização de revisão crítica do conteúdo intelectual; (c) aprovação da versão submetida. Todos os autores declaram para os devidos fins que são de suas responsabilidades o conteúdo relacionado a todos os aspectos do manuscrito submetido ao OBJN. Garantem que as questões relacionadas com a exatidão ou integridade de qualquer parte do artigo foram devidamente investigadas e resolvidas. Eximindo, portanto o OBJN de qualquer participação solidária em eventuais imbróglios sobre a matéria em apreço. Todos os autores declaram que não possuem confli o de interesses, seja de ordem finan eira ou de relacionamento, que influencie a redação e/ou interpretação dos achados. Essa declaração foi assinada digitalmente por todos os autores conforme recomendação do ICMJE, cujo modelo está disponível em http://www. objnursing.uff.br/normas/DUDE_final_13-06-2013.pd

Recebido: 13/04/2016

Revisado: 31/01/2017

Aprovado: 06/02/2017 